\title{
أثر استخدام برنامج ( موهو MOHO ) على جماليات التحريك في الرسوم المتحركة ثنائية الأبعاد
}

علي حسن عبد اللاه محمد ابراهيم الدالي مدرس بقسم الرسوم المتحركة كلية الفنون الجميلة - جامعة المنيا

مقدمة

يدفع النجاح المتواصل لأفلام الرسوم المتحركة شركات الإنتاج الكبرى للبحث الدؤوب عن تقنيات مبتكرة لتجسيد

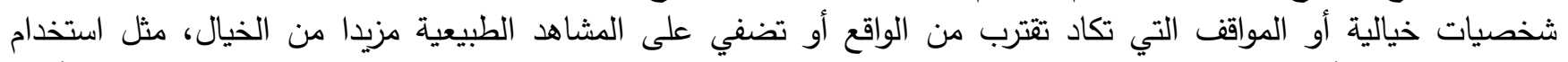

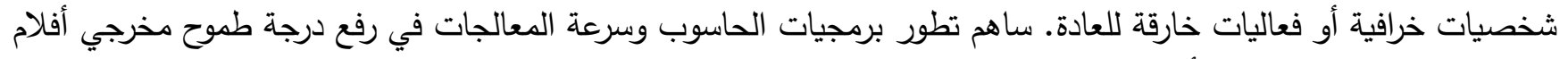

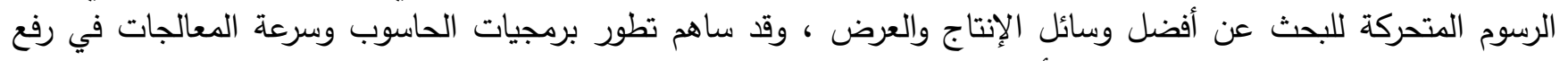

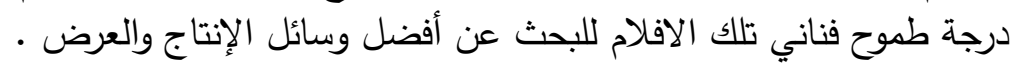

إن التطور التكنولوجي في العصر الحديث بمجال البرمجيات والوسائط المتعددة لهو صخرة تحطمت عليها التحديات

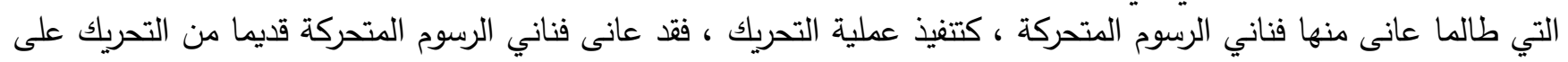

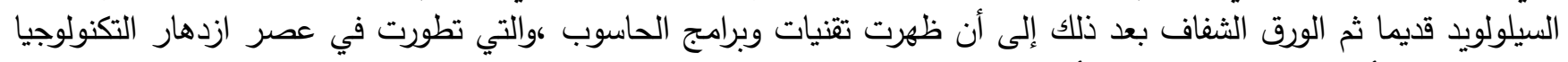

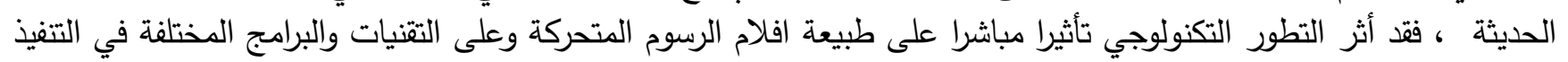

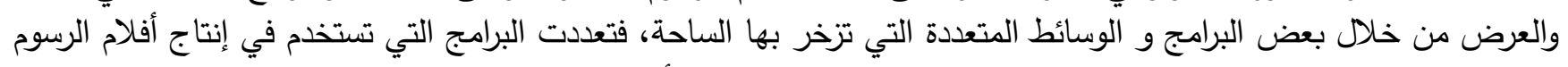

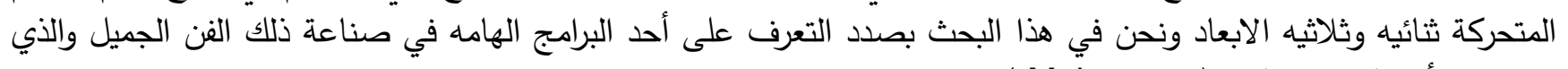

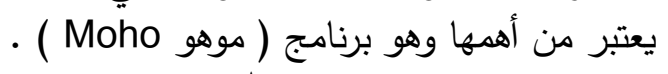

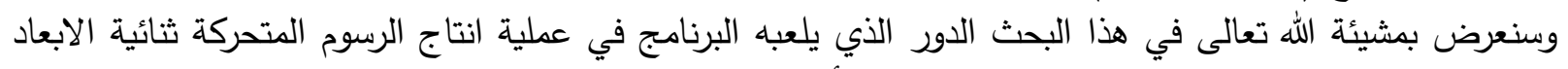

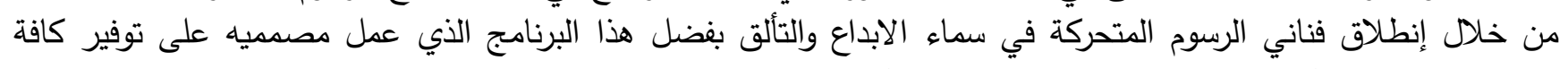

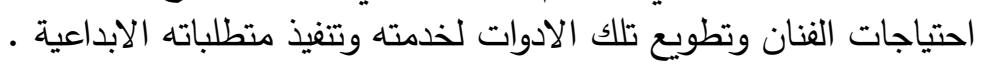

مشكلة البحث :

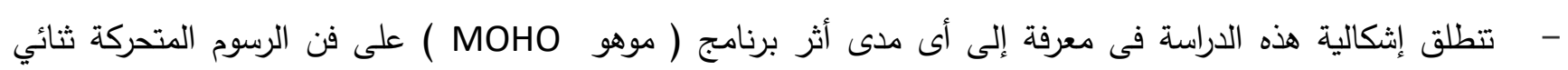
الأبعاد وجمالياته ؟ إنبان

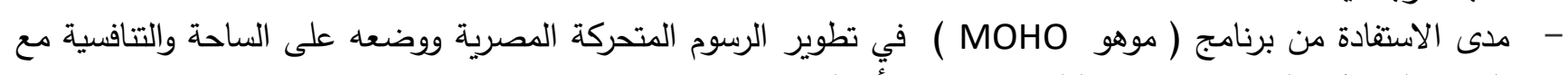
الرسوم المتحركة الغربية سواء من الإناحية موهو الإبداعية أَّ التقنية . أهمية البحث: - - إلقاء الضوء على الضى برنامج ( موهو

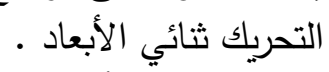

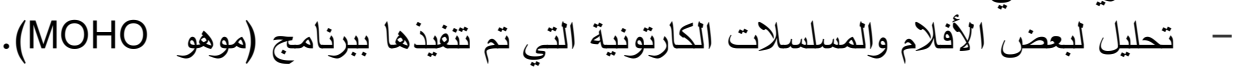

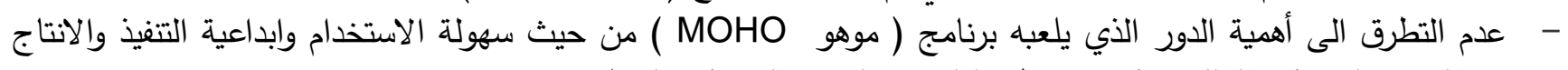

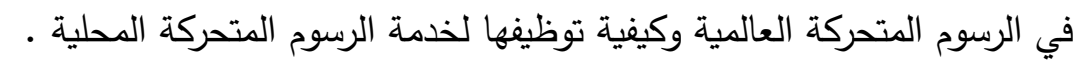

أهداف البحث : البوم:

- التعرف على أهم البرامج المتخصصة ودورها في انتاج افلام رسوم متحركة متميزة .

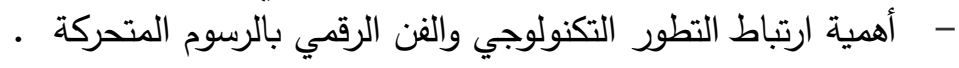

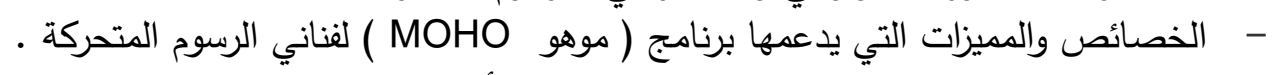

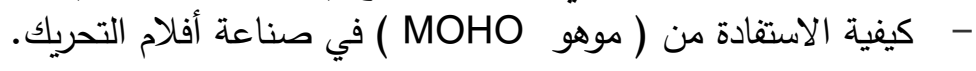

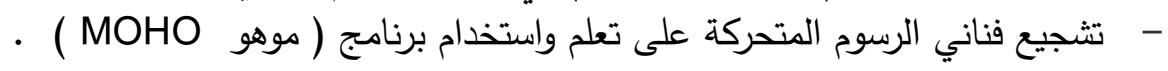


- - هل هناك تهميش لدور التطور التقني والتكنولوجي في الرسوم المتحركة المحلية ؟

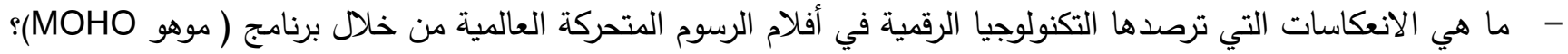

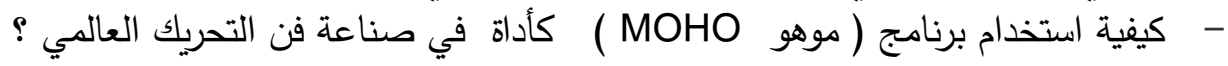

حدود البحث : - - الحدود الزمنية : من 2007 م حتى الان. - - الحدود المكانية : مصر والعالم • من منالم

منهج البحث: - - منتهج الباحث في هذه الدراسة المنهج التاريخي والوصفي و التحليلي

\section{التقتيات الرقمية وأثر ها على الجانب الإبداعى في فن الرسوم المتحركة}

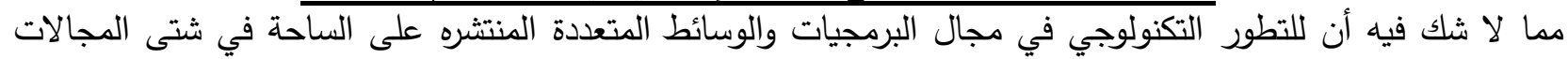

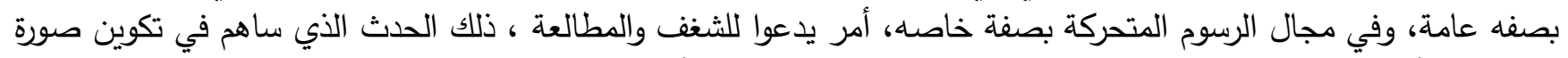

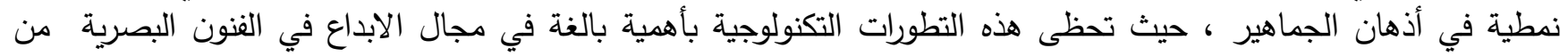

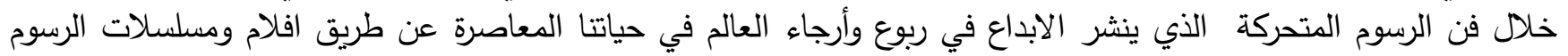

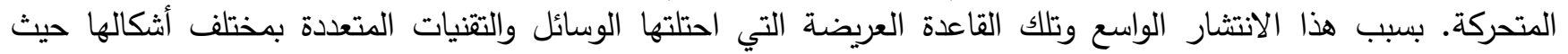

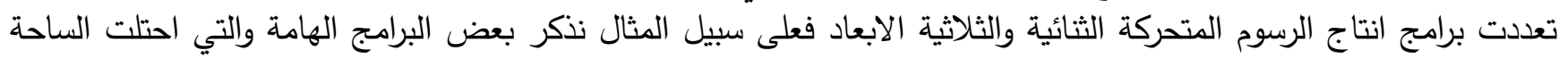

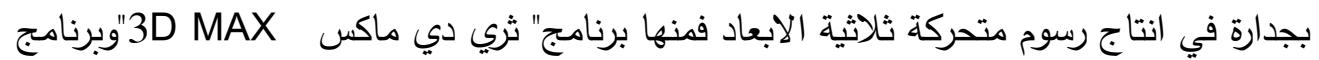

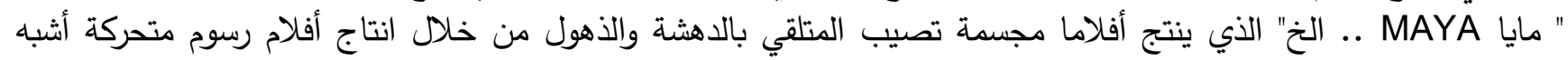

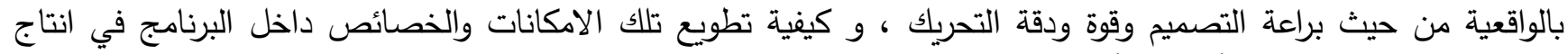

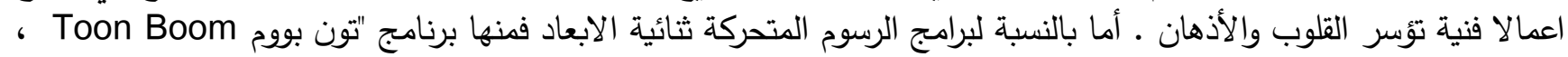

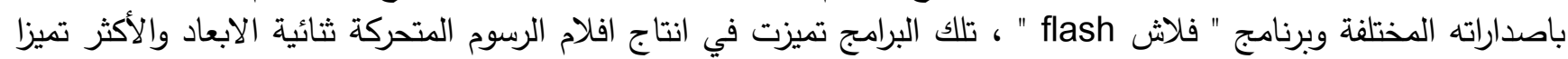

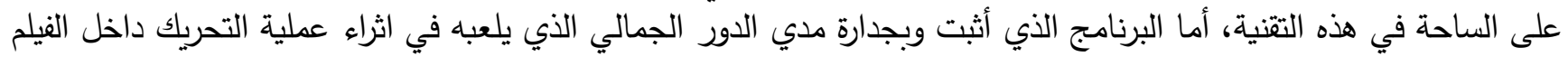

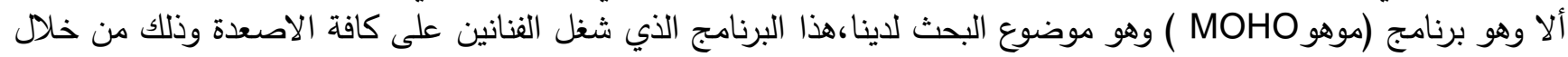

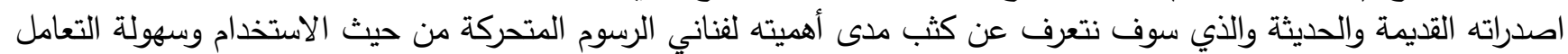

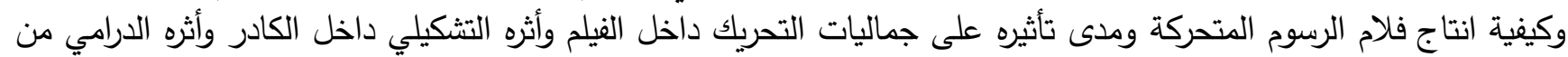

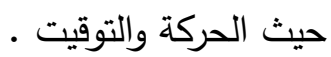
إن ما ينتجه فناني الرسوم المتحركة من مسلسلات وأفلام كارتونية رائعة عن طريق تسخير كافة امكانات برنامج ( موهو

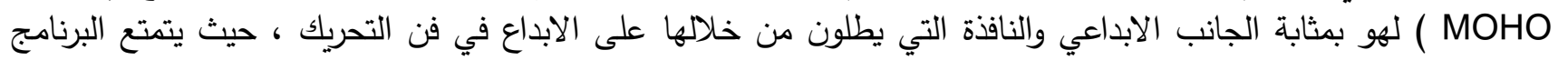

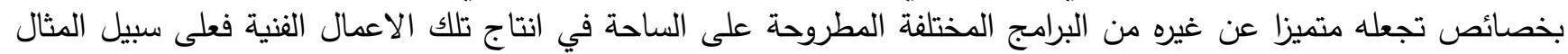

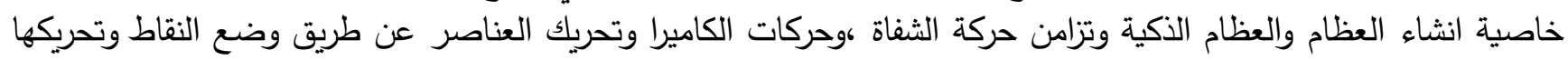

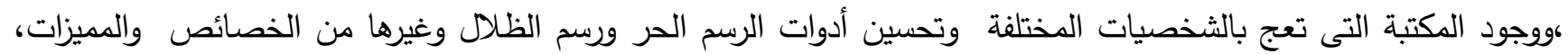

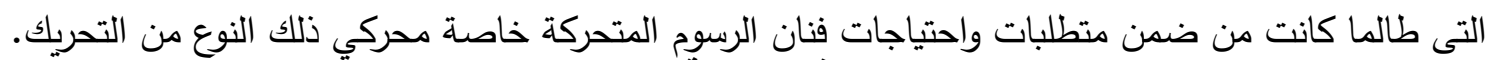

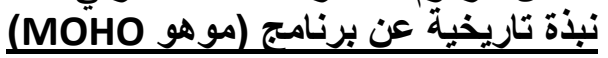

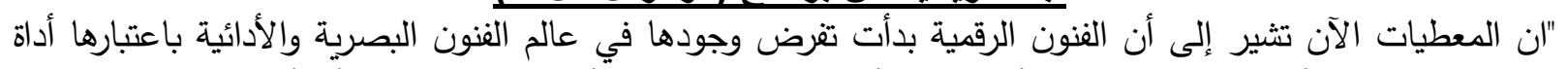

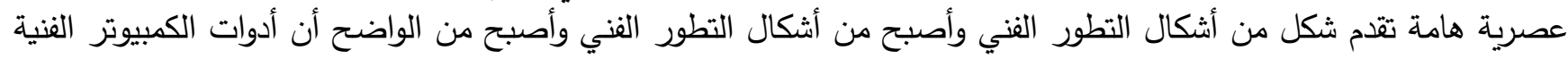

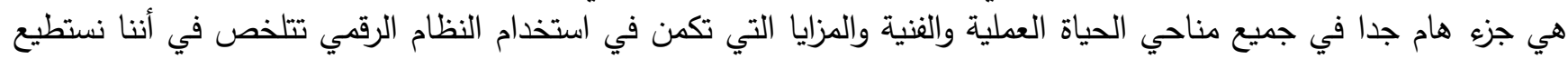

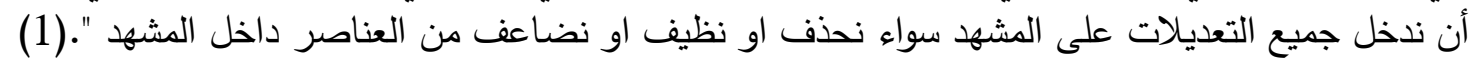
برنامج (موهو MOHO) شكل رقم (1) هو احد البرامج المتخصصة في إنتاج أفلام الرسوم المتحركة ثنائية الأبعاد

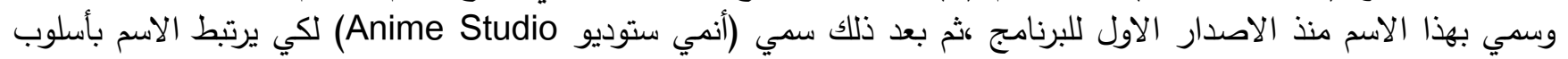

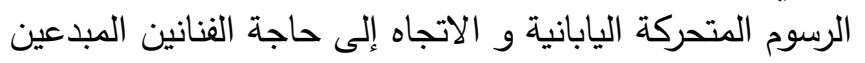

(1) Chad Troftgruben learning Anime Studio packt Publishing Ltd,2014page 4 


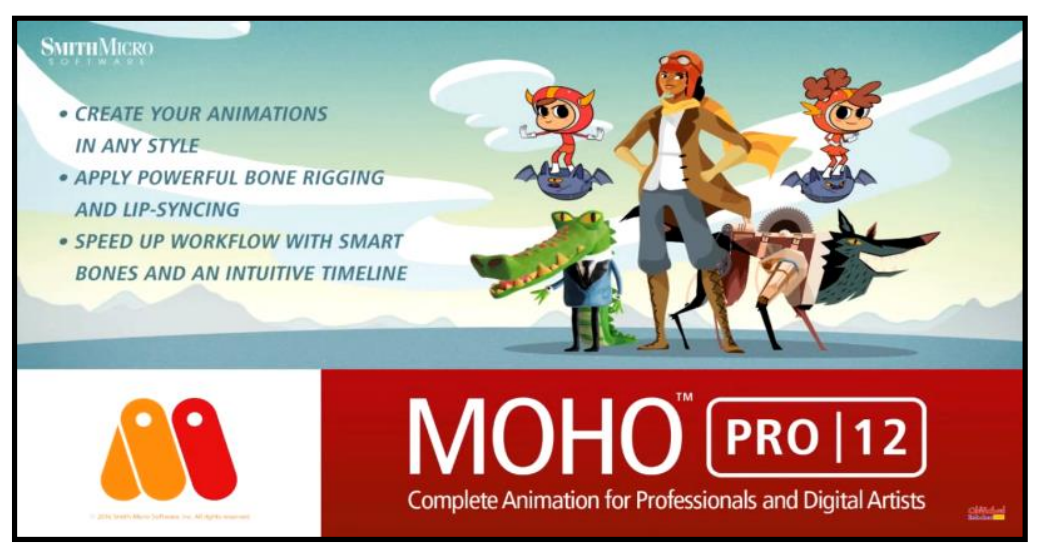

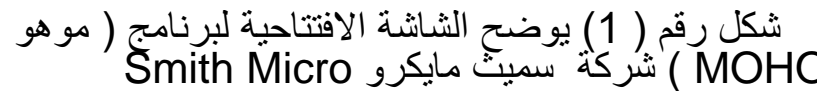

الذين يحتاجون الى مثل هذه البرامج ، ومن

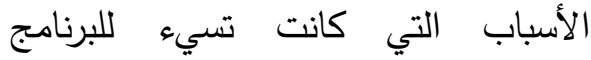
مجموعة المبرمجين الذين قاموا بتتفيذ هذا

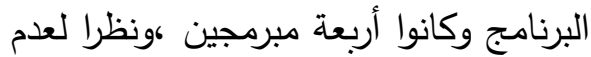

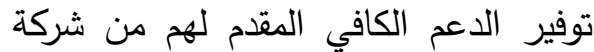

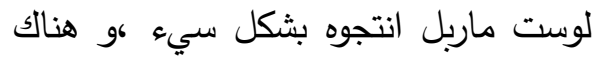
بعض النماذج القديمة الموجودة في المكتبة الخاصة بالبرنامج ويرجع تغيير هذه السمعة

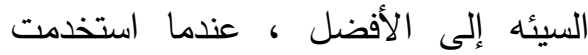

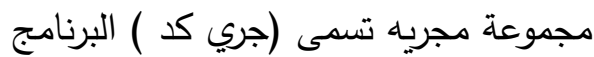
و قامت بعمل مجموعة من الافلام القوية

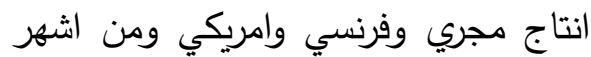

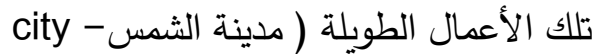
) وهو فيلم رسوم متحركة من (of the sun

إنتاج فرنسي تدور أحداثه في مصر القديمة وتم تتفيذ عمل إماراتي يسمى فواز وكان إعلان لدورة ألعاب عربية مما جعل الأنظار

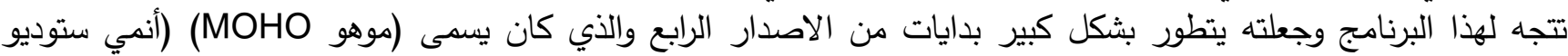

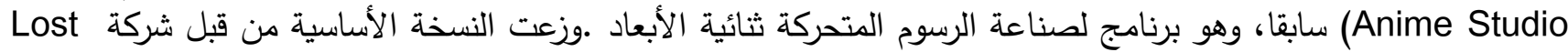

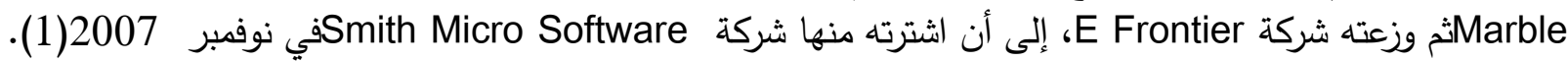

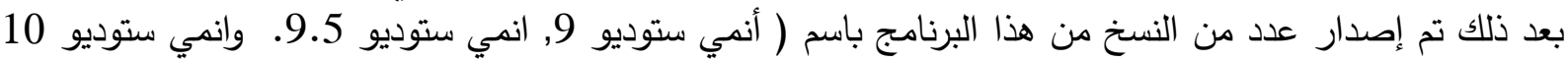

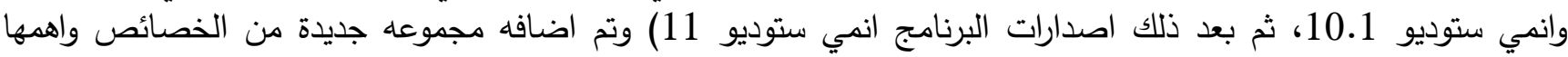
خاصية التحريك (كادر كادر frame by frame) حيث أصبح الآن من المدكن لفنان الرئ الرسوم المتحركه ان يقوم بالرسم المباشر

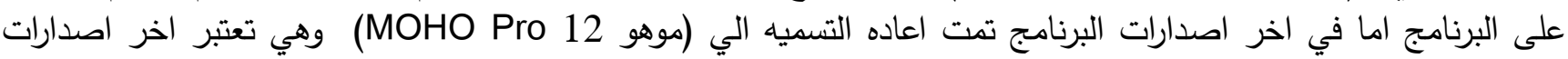

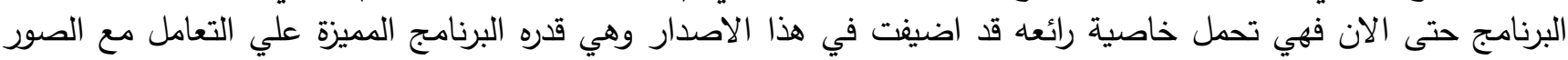

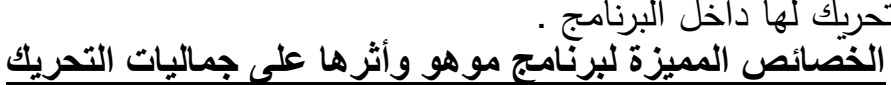

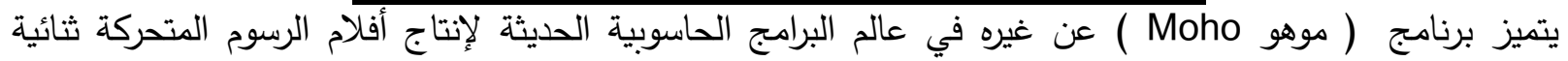

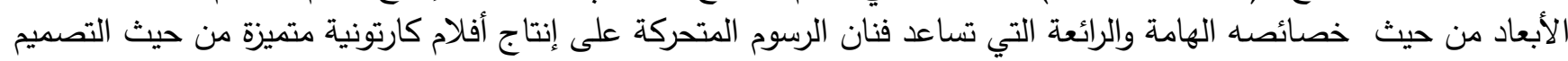

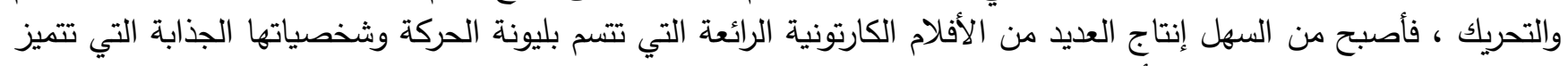

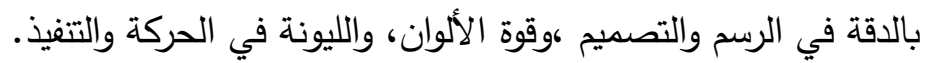

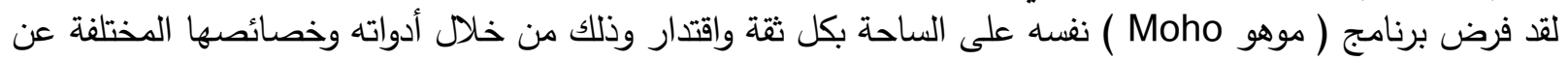

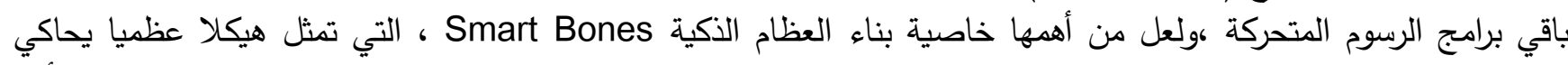

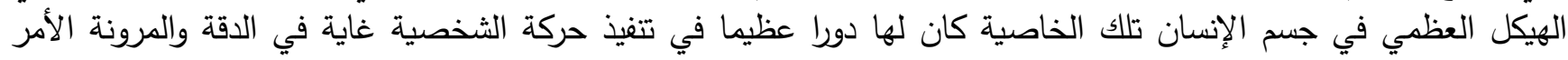

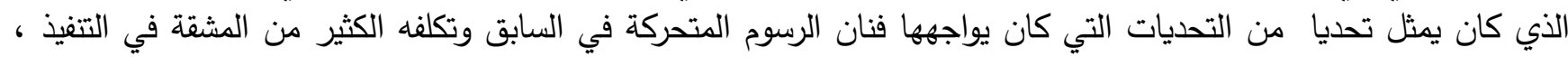

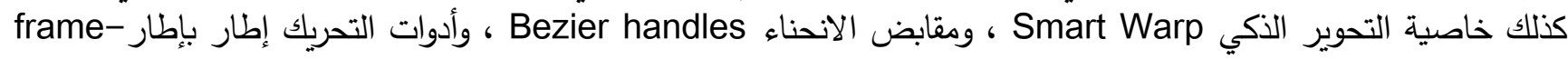

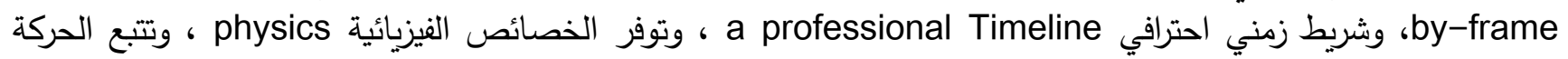

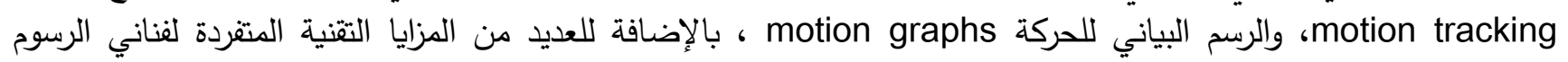

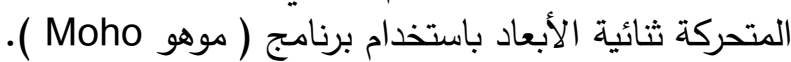

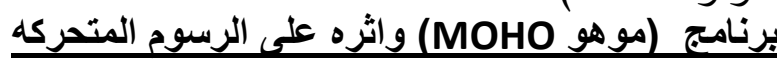

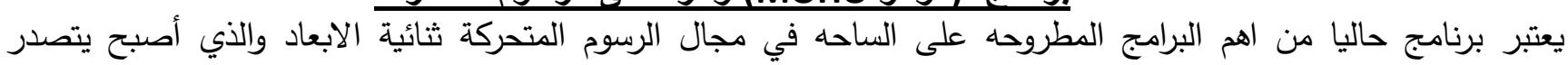

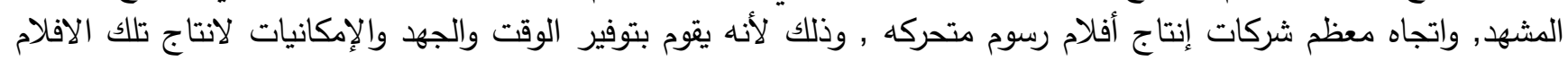

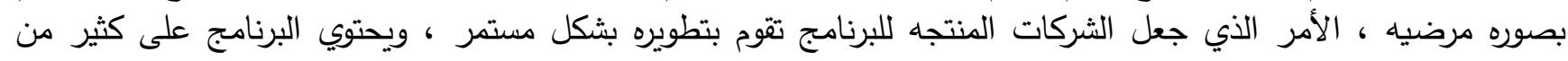

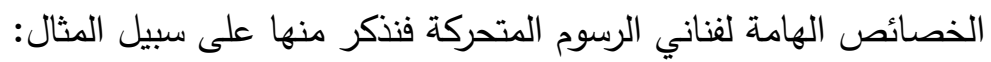




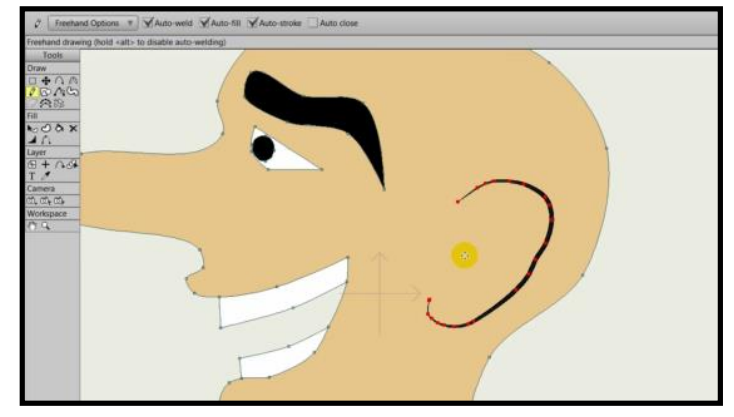

شكل رقم ( 3 ) يوضح تقنية انشاء العظام الذكية داخل ( برنامج موهو (moho )

https://www.youtube.com/watch?v=oW5rqsQ DyRo\&list=PLIGvOGqyAbdIDaZOwgRe7PCY9FB9

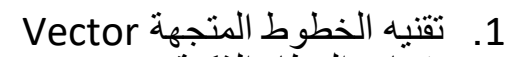
2. تقنيات العظام الذكية Smart Bones

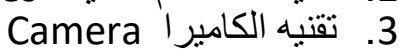
Shadows تقنتيه الظلال

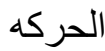
تنظيف 5. 5

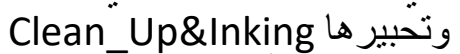

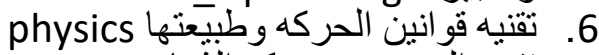

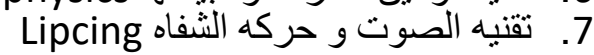

"خاصية فيكتور Vectors التي تعتبر اول

فيكتور Vectors

خاصيه ونقطة تطور واختلاف أحدثتها تلك الشركة المنتجة

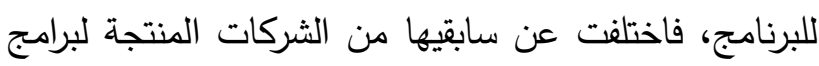

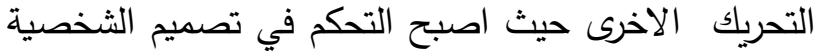

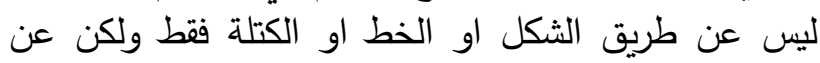

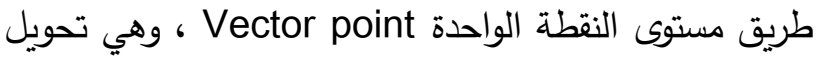

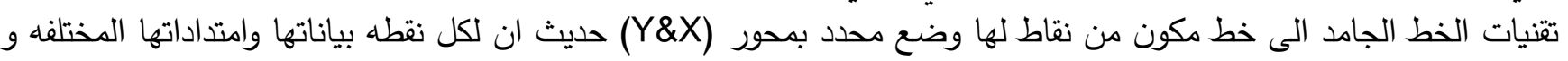
التي تشمل موقعها من الفراغ في مسرح العمل واتجاهها

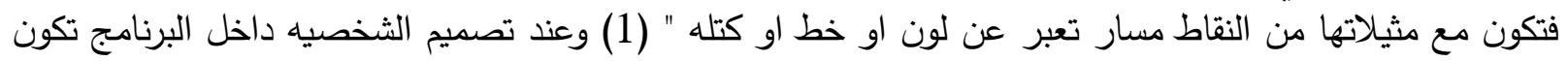

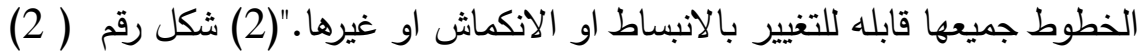

: Smart bones تقية العظام الأكية

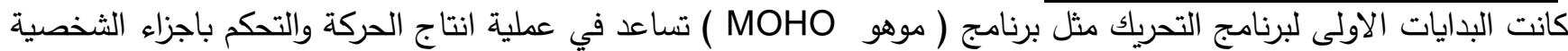
كاملة مثل الاشكال shapes فكان هناك قصور في امكانية تحريك الجسم لشخصية الانسان

او الحيوان له مفاصل وعظام أو قصور في عملية التحريك التي تبدو طبيعية كما هو الحال في برامج الرسوم المتحركة ثلاثية

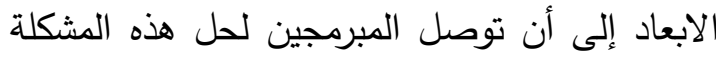

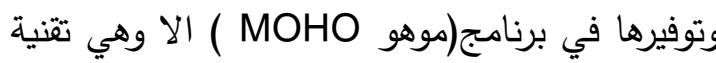

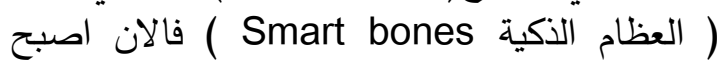
فنان التحريك قادرا على تصميم هيكل عظمي التئي للشخصية ليستطيع تحريك الثخصية بدقة ولئ وليونة اشبه بمثيلاتها للشخصيات الحية في الواقع الحقيقي

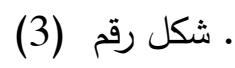

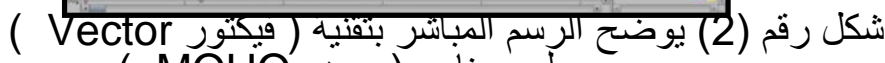

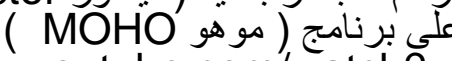

https://www.youtube.com/watch?v=8NpQ5CgH0c0

" زوايا وحركات الكاميرا في برنامج 'موهو MOHO
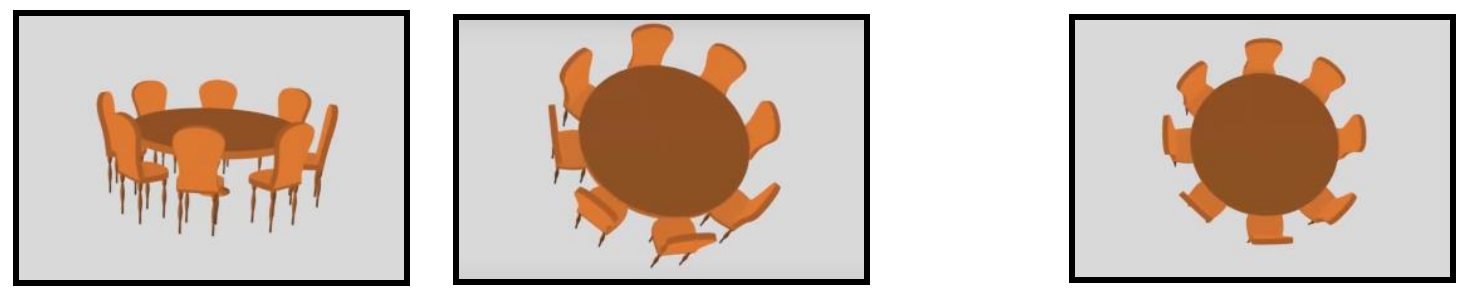

شكل رقم (4) يوضح حركة نزول الكاميرا من أعلى ثم إلى المنظور العادي ثم الدوران

(1) Anime studio pro 11users Manual

(2) Kelly L.Murdock Anime Studio 6 The Official Guide Cengage Learning,2009 pag200 
ان الذي يشغل بال المخرج في انتاج فيلم رسوم متحركه هو كيفيه وضع زوايا الكاميرا وحركاتها داخل الكادر واحجامها ليس نابعا

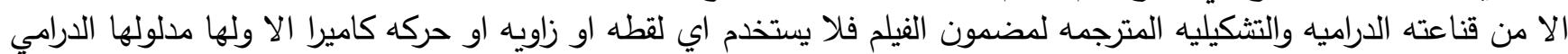

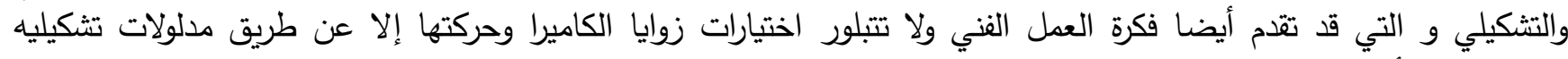

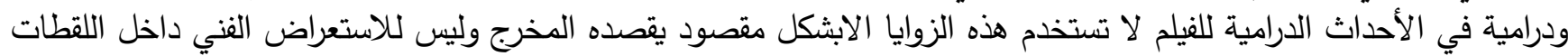
فقط ومن هذا المبدأ يستخدم الفنان برنامج " موهو

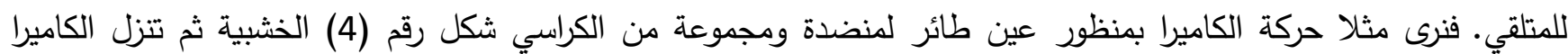

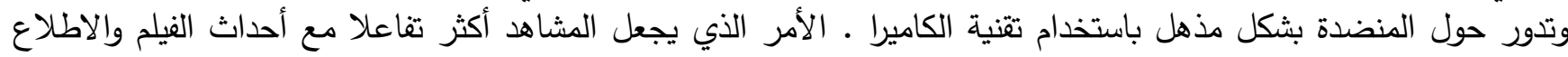

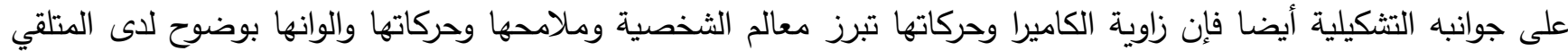
ليشاهد عن كثب ماهيه الثخصية الكارتونية وطبيعتها الامر الذي يجعله يغوص في أعماق تلك الثخصية، الثاتية ومن ثم ايضا اظظهار

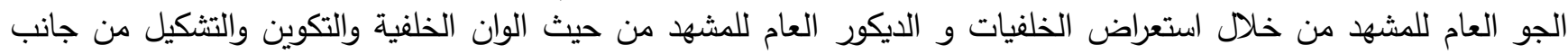

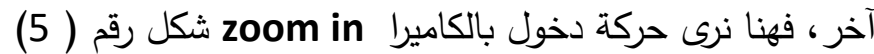

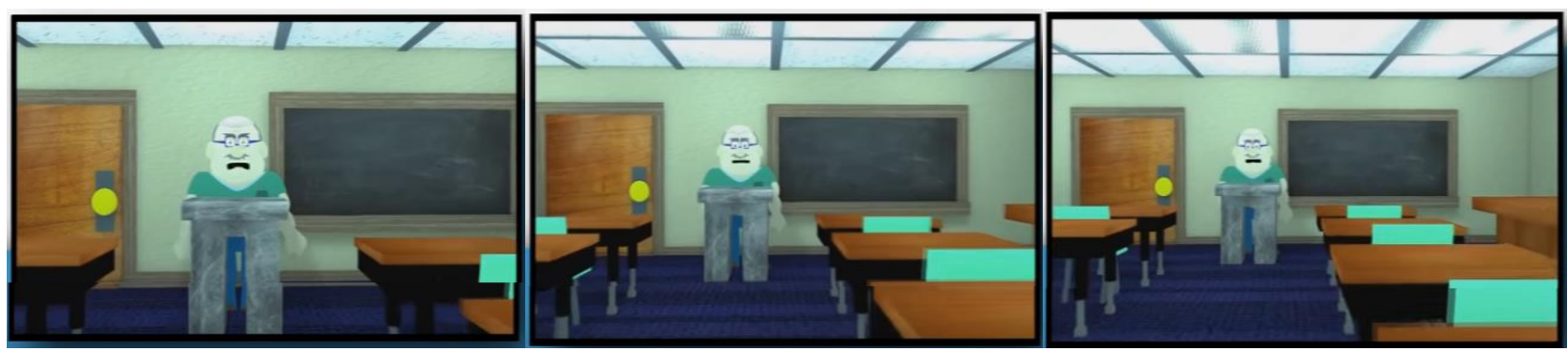

شكل رقم ( 5 ) يوضح حركة zoom in بالكامير ا داخل برنامج ( موهو MOHO )

https://www.eskchat.com/article-1204.html

كما احتوى برنامج موهو moho على العديد من الامكانيات الجديدة ومنها على سبيل المثال :

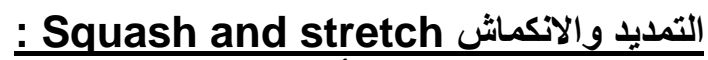

"وهى واحدة من أهم خصائص التحريك الكرتوني ، فعند تمدد طول الثكل ينكمش العرض والعكس، وخاصية التمدد والانكماش تضفي حياة على الرسوم الجامدة وتعطي متعة عند المشاهدة."(1) شكل رقم ( 6 (

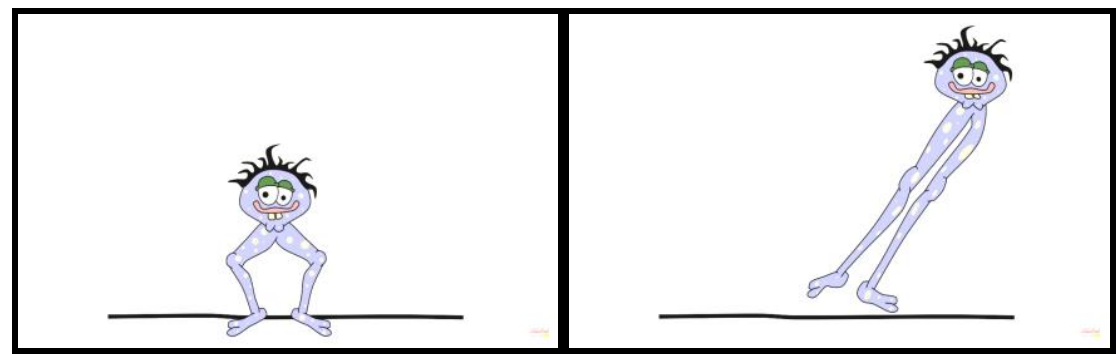

شكل رقم (6) يوضح كيف يقوم الفنان بانبساط و انكماش الثخصية باستخدام (برنامج مو هو MOHO)

https://www.eskchat.com/article-1607.html

Bezier handles مقابض الانحناء

(1) https://www.eskchat.com/article-1607.html 


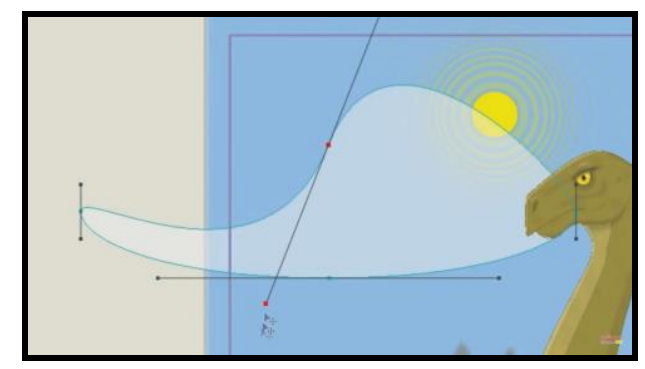

شكل رقم (7) يوضح تقنية مقابض الانحناء داخل داخل برنامج (موهو (MOHO)

https://www.youtube.com/watch?v=Q5CGrWz6gA8

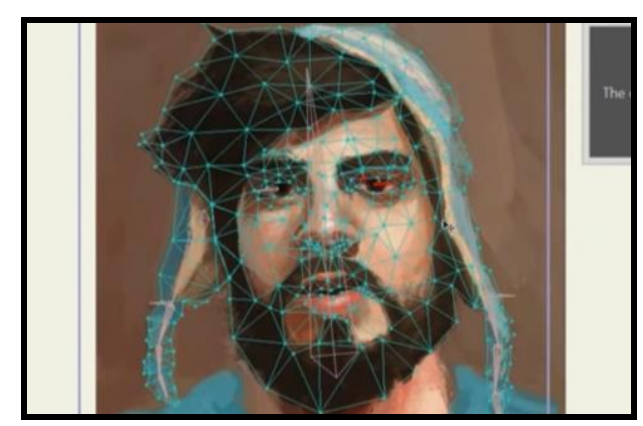

شكل رقم ( 8 ) يوضح تقنية التحوير الذكي Smart warp داخل برنامج (موهو MOHO

https://www.youtube.com/watch?v=Q5CGrWz6gA8
والتي توجد في العديد من برامج الجرافيك

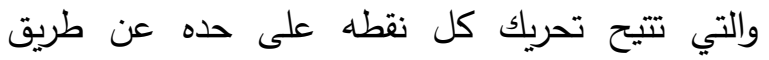
المقابض والتي بدورها تقوم بتسهيل عملية الرسم وتجعله تصنه

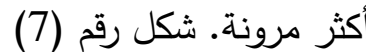

Smart warp تقية التحوير الذيكية

التقنية الجديدة في برنامج (موهو تتيح سهولة تحريك وتحوير الصور داخل البرنامج بسهولة واحترافية شديدة من خلال رسم مجموعة نقاط نقاط موزعة على الصورة ومن ثم ربطها بخاصية التحوير

الأكي

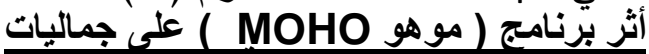

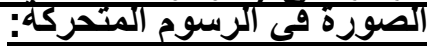

أصبحت التكنولوجيا الرقمية تشكل أداة أساسية

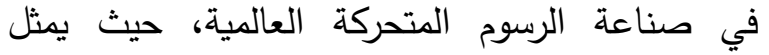
برنامج ( موهو MOHO ) بالأساس إلى فناني الرسوم الرئي

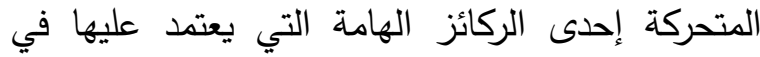

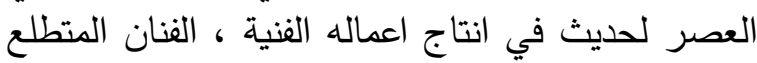
على كل ماهو جديد في عالم التقنيات الرقمية ، والذي التي التيان

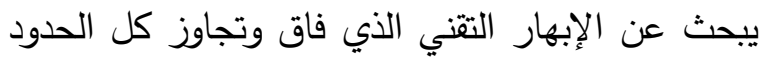

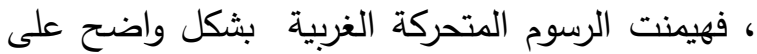

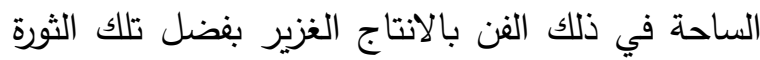
الرقمية، واحتلت عقول الأغلبية من المشاهدين بما تقدمه من جمال في الصورة ودقة بالغة في جماليات الإتئ من الحركة. برنامج ( مؤهو MOHO ) والمؤيثرات البصرية

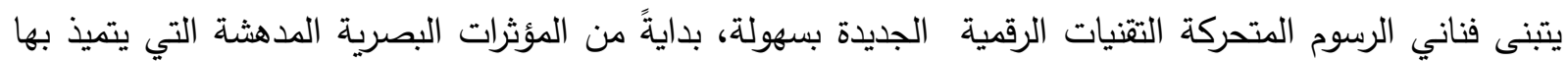

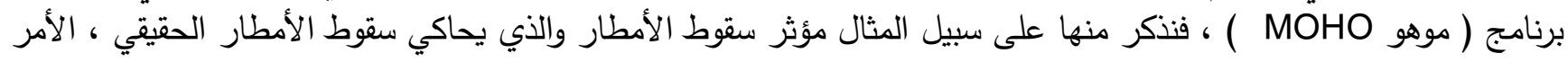

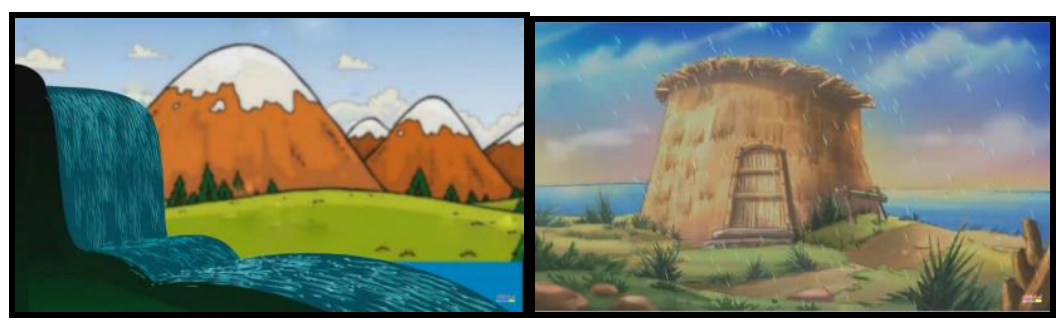

الذي يكسب العمل الفني

شكل رقم ( 9) يوضح خاصية المؤثرات

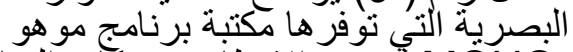

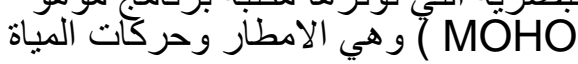

https://www.eskchat.com/article4705.html

الصبغة الابداعية التي لإني يحظى بها الفنان لاخراج

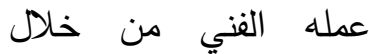
امكانيات البرنامج شكل

Mask تقنية تنفيذ القناع تقنية عمل قناع للطبقة من الخصائص الجميلة التي لتئي يتميز بها برنامج ( موهو 
(Moho

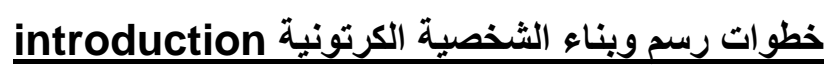

تعتبر الثخصية هي الركن الاساسي والعنصر المحوري الذي يقوم عليه العمل الفني في فيلم التحريك فقد تمر بعدة مراحل

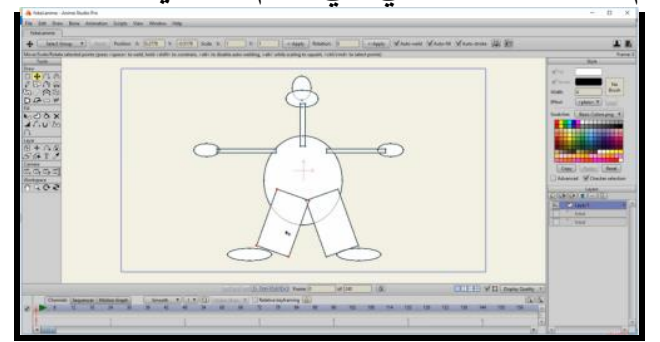
نستعرضها كالتالي:

•

والسلوكية .

• بدء تصميم سكتش ورسم أولي للشخصية .

شكل رقم ( 11 ( 11 )

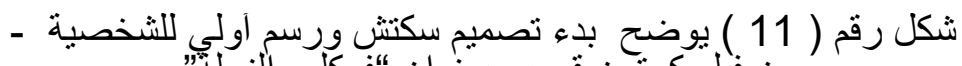
من فيلم كرنون قصير بعنو ان “فوكل و النحلة". • عملية التلوين للشخصية (11) ورسم التحبير https://www.eskchat.com/article-3541.html stroke رسم الملامح. شكل رقم (12) ثم يلي ذلكاء

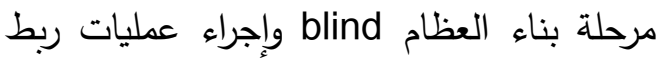

العظام بالنقاط points أو الطبقات layers أو بالربط المرن flexibility ، يتبعها تصميم قيود العظام Constraint

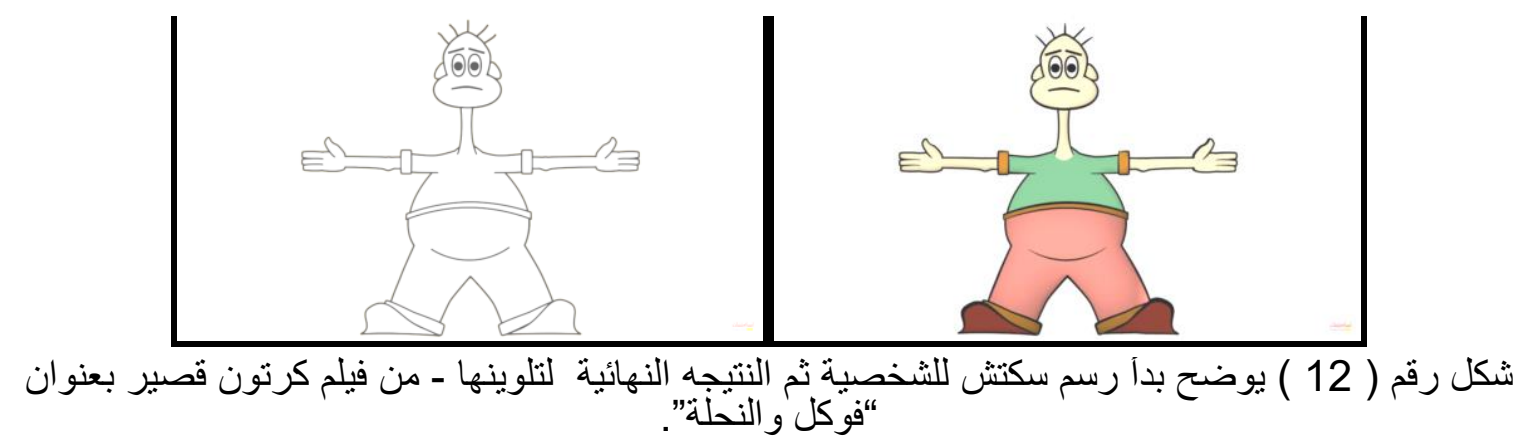

https://www.eskchat.com/article-3541.html

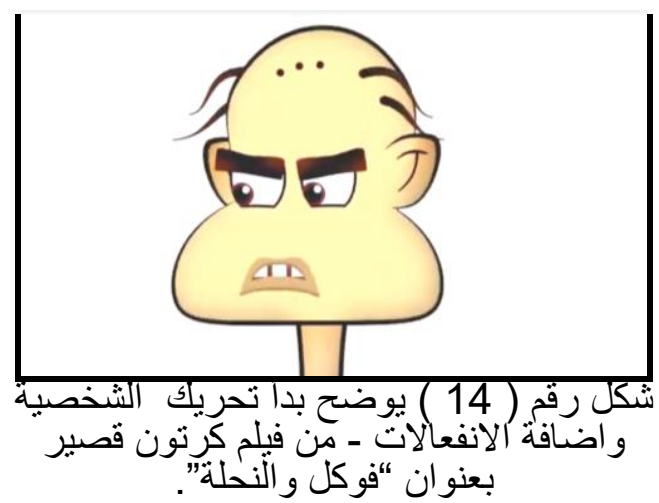

https://www.eskchat.com/article3541.html

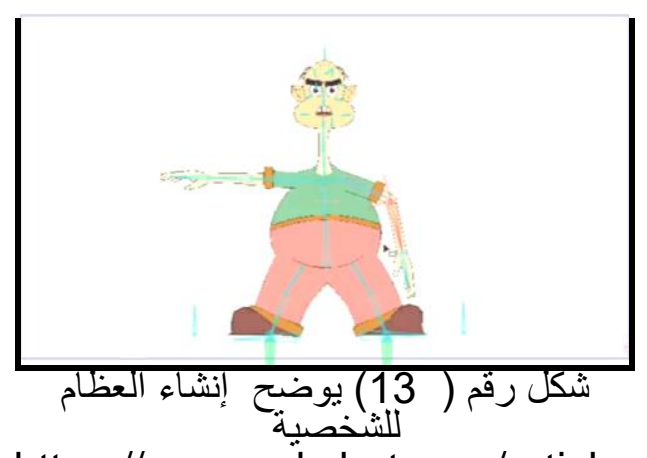

https://www.eskchat.com/article3541.html

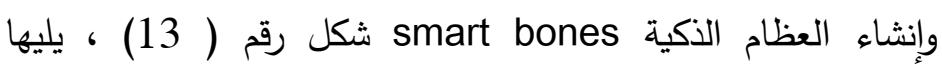
تصميم الشخصية من الاتجاه 
الجانبي side ومن الخلف back ، ثم تبدأ مرحلة تصميم الإجراءات actions وتتضمن حركة المشي walk والجري run والتهري

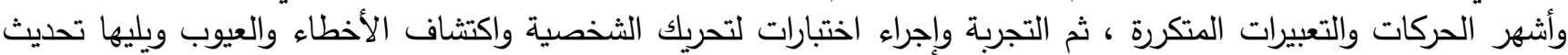

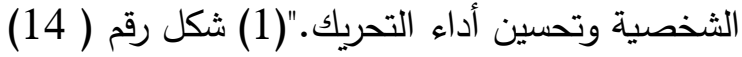

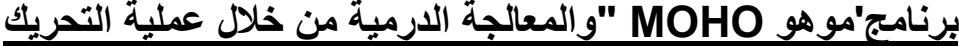

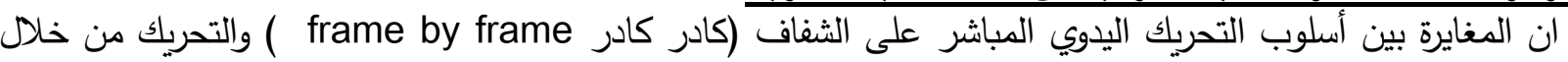

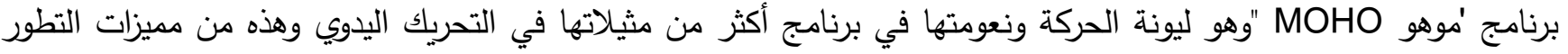

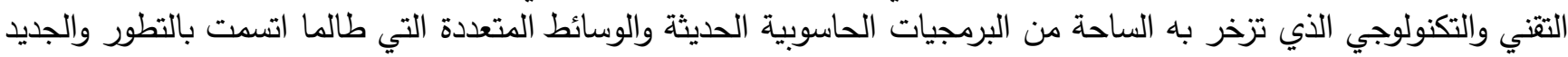
، وهكذا وجد فنان الرسوم المتحركه ان استخدام برامج الحاسب الآلي بصفة عامة وبرنامج " موهو خاصة قد يكون سببا في اظهار وابراز ووضوح الفكرة الدرامية، فيعدد الفنان على استخدام البرنامج لتلبية رغباته وابدان وابداعاته في

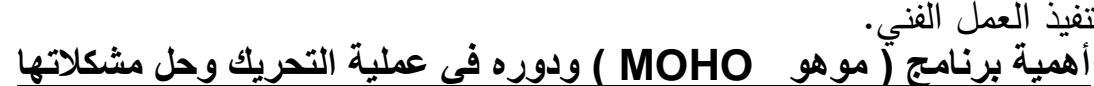

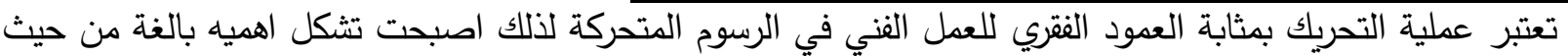

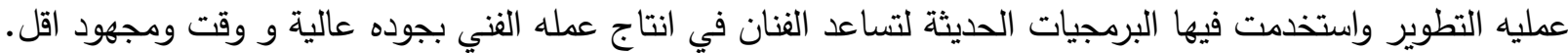

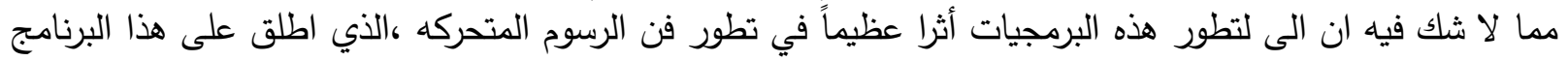

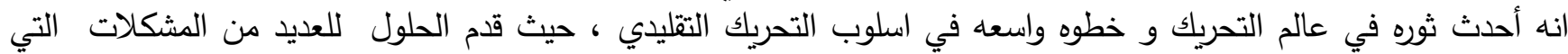

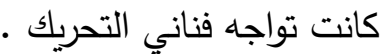

لقد أضفى برنامج (موهو وعمل البينيات بثكل غاية في السهولة والروعه ، حيث أنه ينتج رسوما متحركة بخاصية Vector لتتفيذ الرسوم المتحركه ثنائيه الابعاد وهي التي تتسم بالدقي في الخطوط في الخوط وقوه ونقاء اللون.

فمن أبرز المشكلات التى تواجه فنان التحريك التقليدي وكيفية حلها في برنامج ( موهو Moho ) )

تبدا عمليه التحريك بعد تصميم المشهد وتعتمد على تحويل هذا المشهد او النقطه الثابته الى حدث ينبض بالحئه بالحياه كل

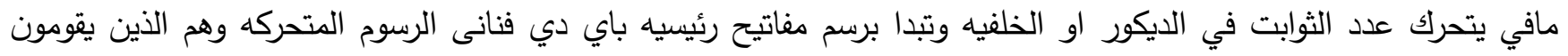

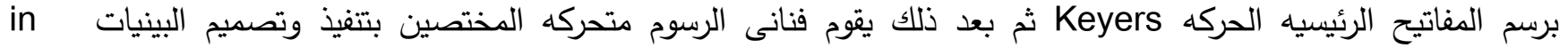

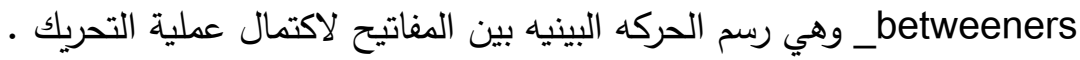

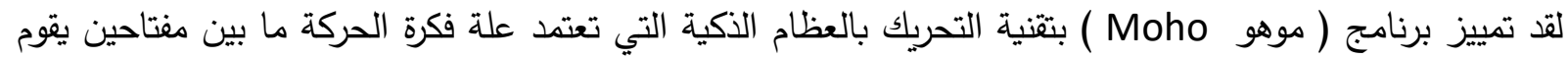

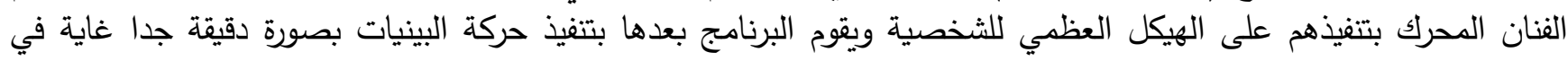

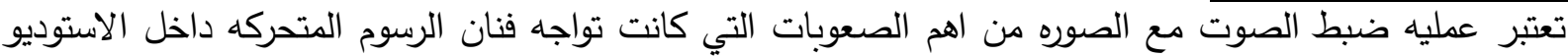

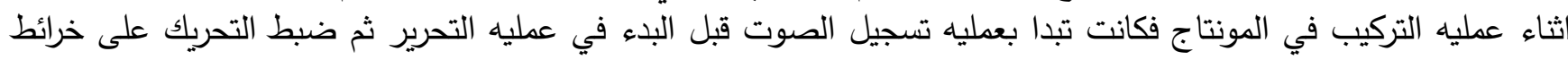
الصوت بحسابات خاصه ولكن بعض الاستوديوهات والشركات مثل (فلشر فيلم flesher film ) كانت تسجل الصوت فئل فعد عمليه التحرير وفي جميع الحالات كان هناك دائما صعوبه في هذه المرحلة الدقيقه وخاصه في ضبط فيط تزامن الثفاه الحركة. والتي قام برماج موهو moho
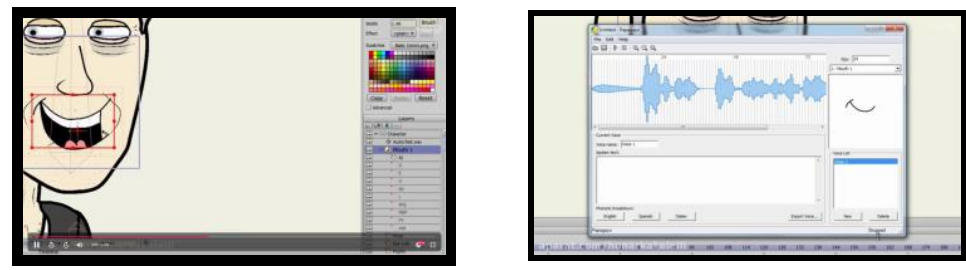
بحل تلك المشكلة

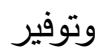
تقنية ضبط

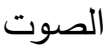

(1) https://www.eskchat.com/article-3541.html 


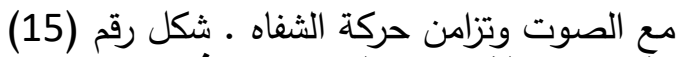
اتقان رسم الثخصيه الواحده من فنان لاخد

تعتبر مشكله تعدد الفنانين المحركين للشخصيه الواحده مشكله هامه تواجهها الرسوم المتحركه المحليه و التي تقوم بطبيعه

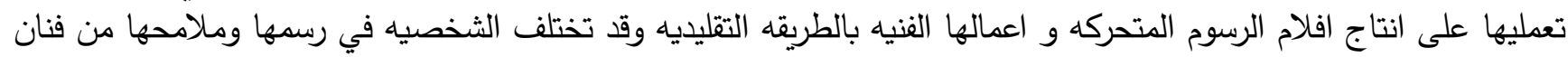

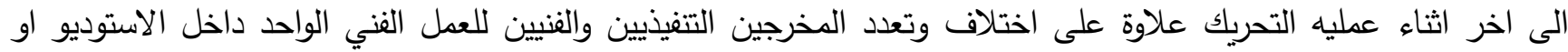
الشركه بالرغم من ان الفنان يقوم بالتدريب على الثخصيه ورسمها قبل القيام بعمليه التحريك والاطلاع على (Model sheet)

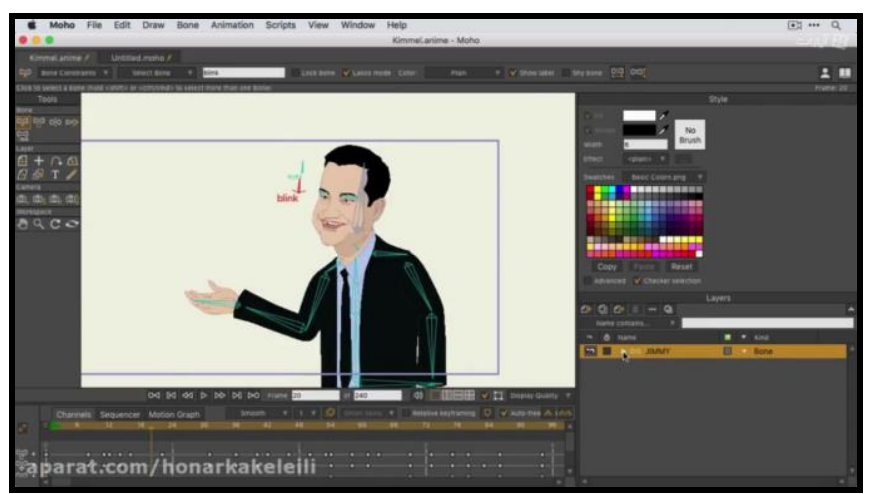

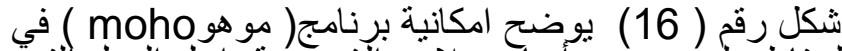

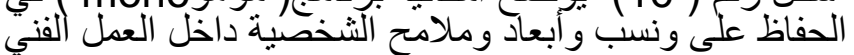
https://www.aparat.com/v/Qlyeb/Moho_12_\% 28Anime Studio\%29 -

SVG_Vector_Graphic_Import_and

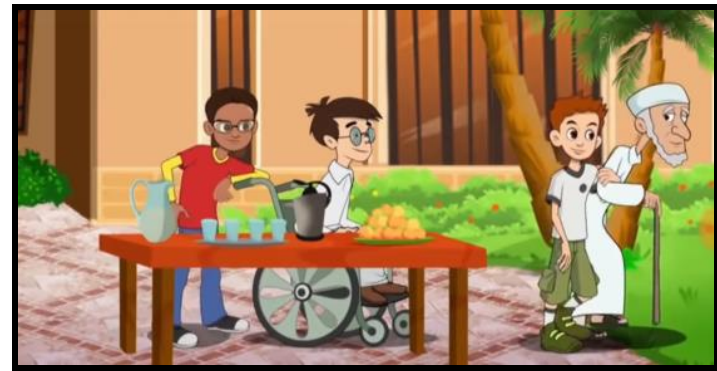

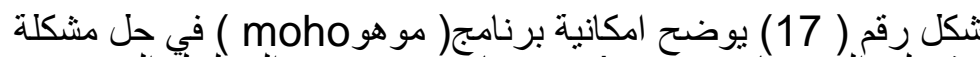

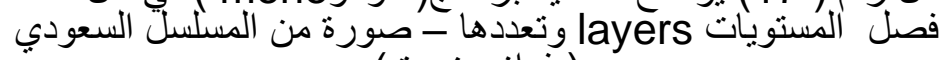

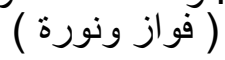

https://www.youtube.com/watch?v=yQoaUNsSgdw

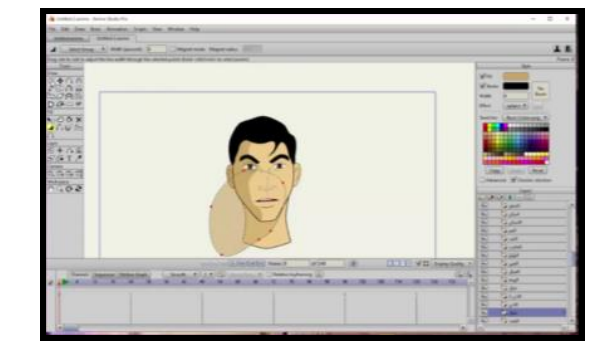

(موهل رقم (18) يوضح طريقة رسم وتحريك الظل في برنامج

https://www.youtube.com/watch?v=GZqjyD4AwHs

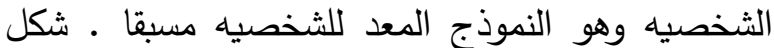

وبالرغم من كل هذه الاحتياطات الواجبه نجد ان في في الإني

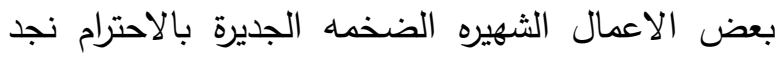

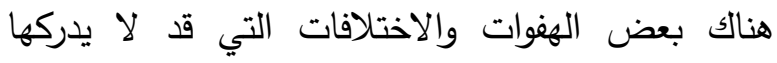

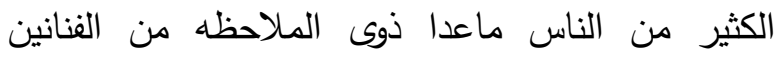

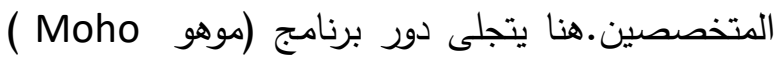

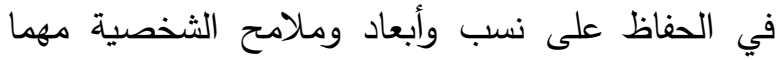

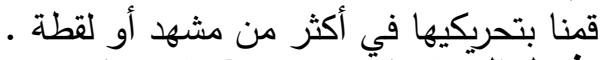

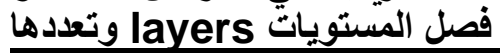

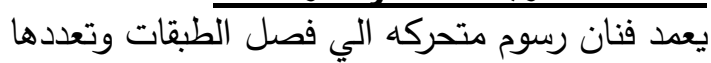
عندما يكونوا في المشهد الواحد او اللقطه الواحده اكثر فئر التهن

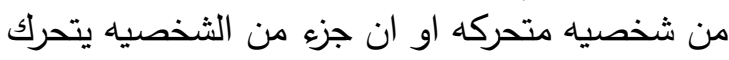
وباقي الشخصيه ثابت يقوم بفصله اون جن

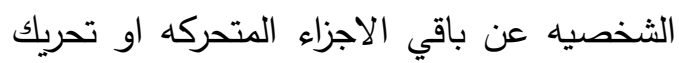

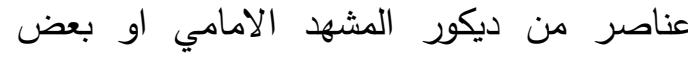

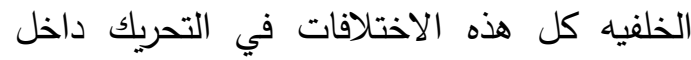

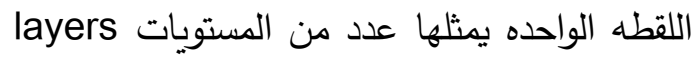

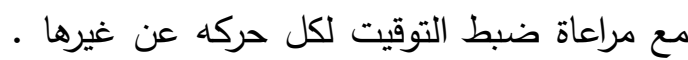

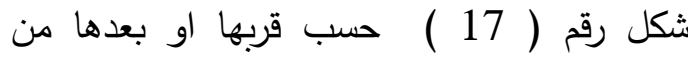

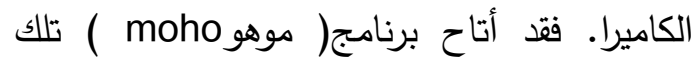

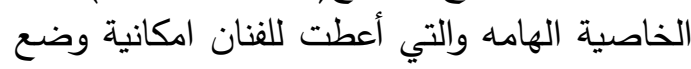

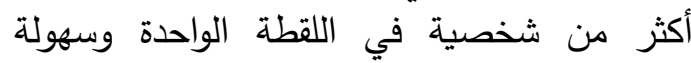
تحريكها هن

\section{تحريك الظلال}

يتوجب على فنان الرسوم المتحركه اثناء

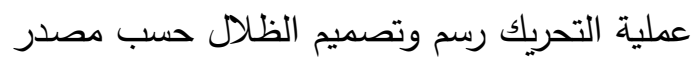
الاضاءه وحسب المنظور المناسب لزويه الرؤية و

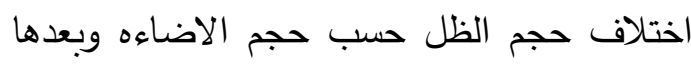
عن الشخصيه، كانت تلك المشكله دائما ما تؤرق الفي الفنان المحرك وهي عدم ضبط والظل بصن بصوره دقيقه.الان اصبح من السهل داخل برنامج (موهو Moho

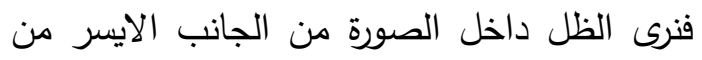
رأس الثخصية وسهولة الرسم ووضع الظل أيضا 
على منطقة العنق ومن ثم تحريك الرأس عن طريق التحرك ووضع مفاتيح الحركة على التايم لاين ثم تحريك الظل على الوجه

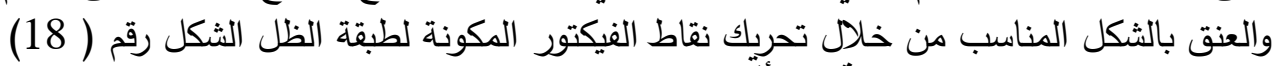

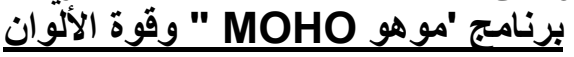

"إن اختيار الألوان داخل أي فيلم رسوم متحركة لابد أن يكون يتكئ على جوانب تثكيلية ونفسية تؤكد الإطار الدرامي

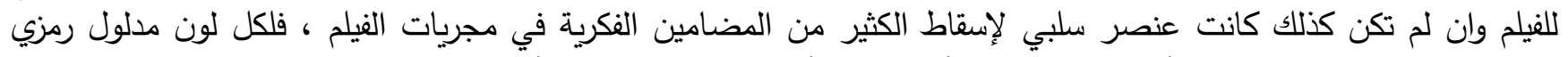

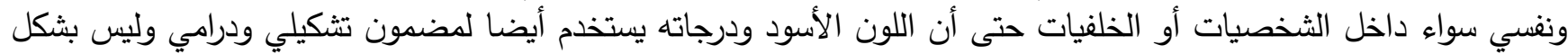

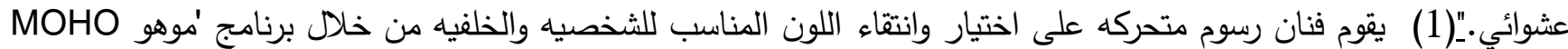

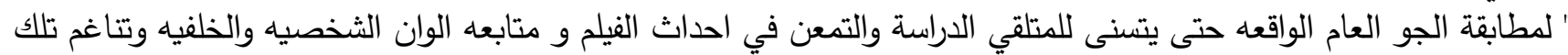

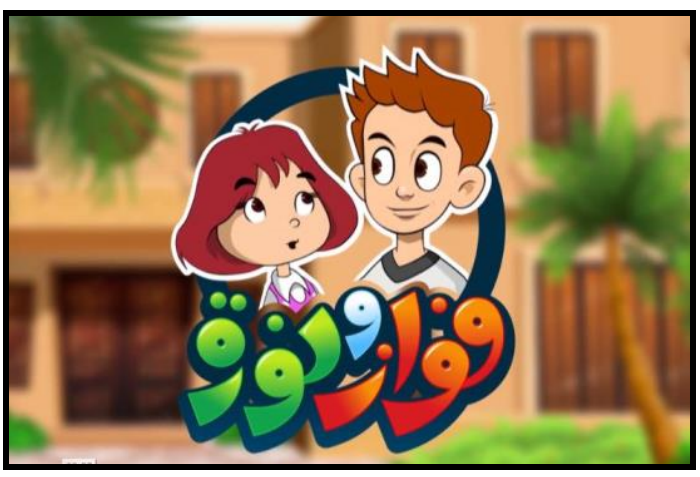

شكل رقم ( 19 ) يوضح افيش المسلسل السعودي " فواز ونورة " تم تنفيذه

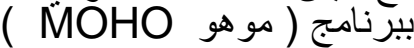

https://www.youtube.com/watch?v=H_PUj05FWvM

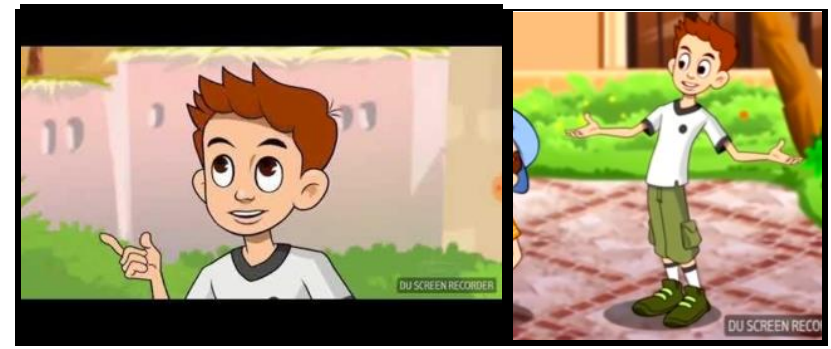

شكل رقم ( 20 ) يوضح تصميم شخصية فو از و وتنفيذها باستخدام

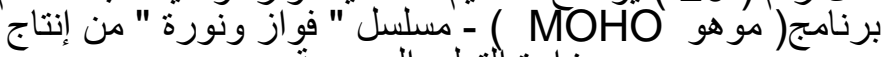
وزارة التعليم السعودية.

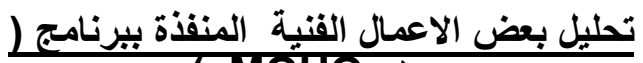

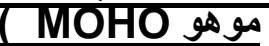
نجح المبدعين في فن التحريك من انجاز العديد

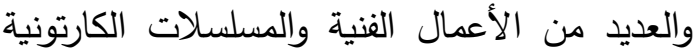

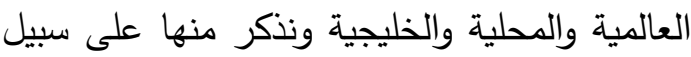

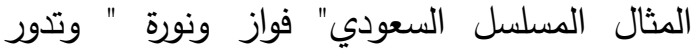

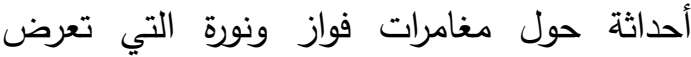
الكثير من المواقف الكوميدية التي يتخللها الوعظ

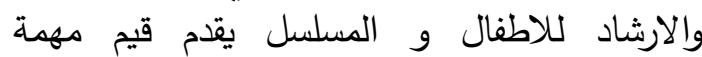

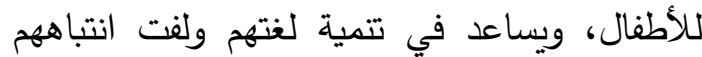
إلى الأخطاء التي يقعون فيها، كما أنه يعند المواقف في قالب كوميدي واعظ، وهو باللغة العربية الفصحى. شكل رقم (19)

"الثخصيات المحورية داخل مسلسل "فواز ونورة آولا: شخصية فواز (البطل)

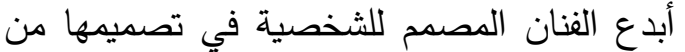
حيث النسب التشريحية للجسم فهي نسب ناجحه لطفل في عمر الثناية عشر تميزت ملامح البطل فئل

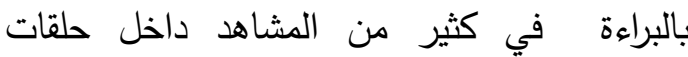

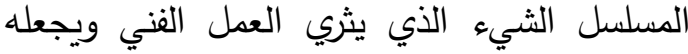
متقبلا لدي المتلقي ، شكل رقم (20 ) لألري العمل

\section{https://www.youtube.com/watch?v=8T5eNEldXTU}

ثانيا : شخصية نورة (البطلة )

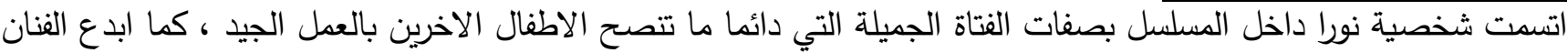

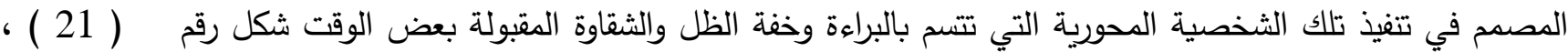
فقد اهتم الفنان بتصميم الشخصية من حيث النسب التشريحية المثالية للشخصية الكارتونية فنرى الرأس الذي يثبه فاكهة الكمثرى والتي يعلوها الثعر الاحمر القصير الذي يزين الجمجمة واهتم ايضا باضافة العينان المستديرتان وانف صغير جدا وفم صغير

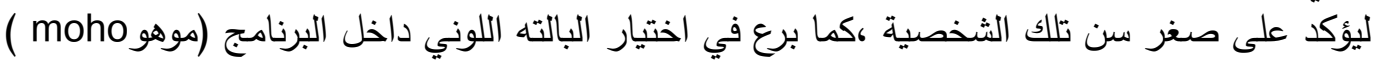




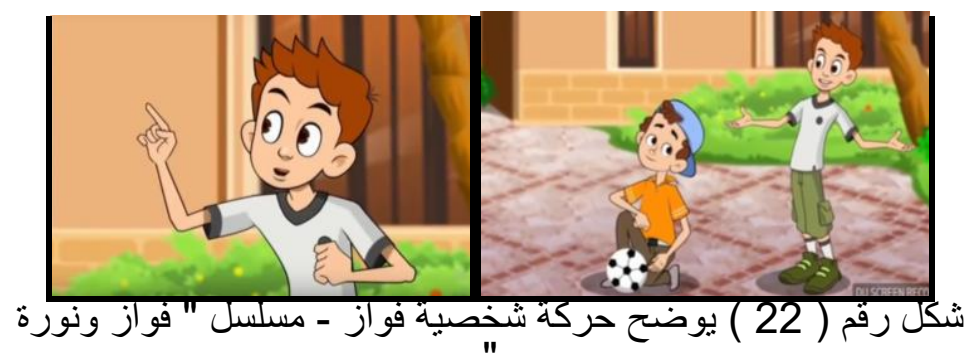

https://www.youtube.com/watch?v=8T5eNEIdXTU

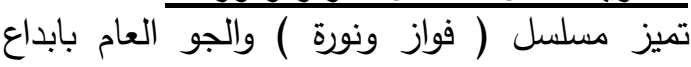
ونعومة وليونة الحركة الامر الذي لفت أنت انتبا الكبار

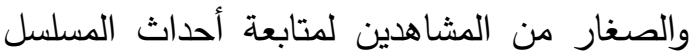

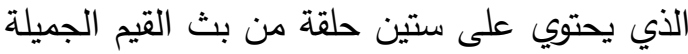

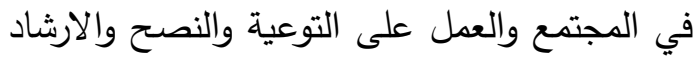

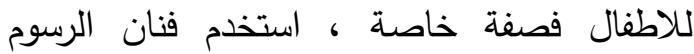
المتحركة تقنيات التحريك التي يوفرها برنامج موهو

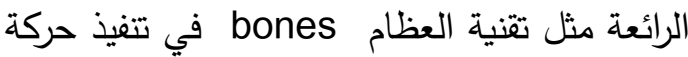

الشخصية ـ شكل رقم (22 ) منئ )

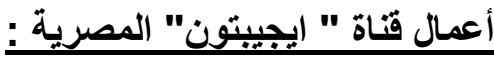
"إيجيبتون " بالإنجليزية (Egyptoon) :هي مشروع قناة كارتون كاريكاتوري ساخر مصرية مستقلة على يوتيوب .متتاولة قضايا

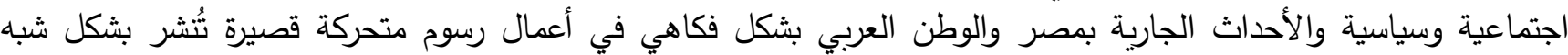
شهري" .(2) وهي حلقات كارتونية منفصلة نفذت ببرنامج ( موهو Moho ) فقد برع فريق العمل من الفنانين المصريين .

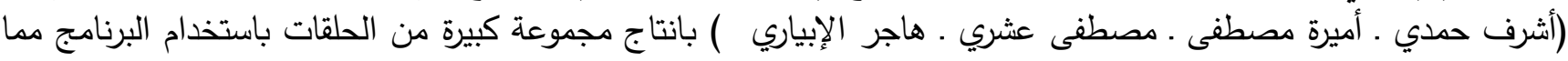
لمسوه في البرنامج من جمال الصورة وسرعة ودقة التحريك وسهولة التعامل مع بناء الثخصيات وحركتها داخل الاعمال الفنية

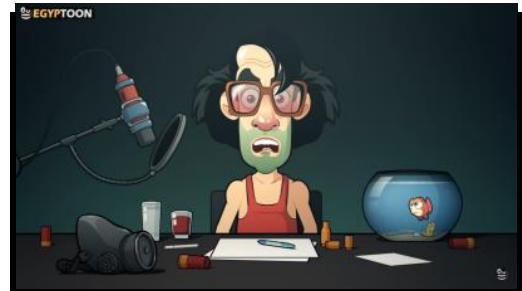

شكل رقم (23 ) شخصية "ايمون المجنون" - ايجيينون Egyptoon

https://www.youtube.com/Egyptoon

تميزت الاعمال الفنية التي قدمها الفنانون بالروعة في تصميم الثخصيات والخلفيات ودقة وليونة التحريك

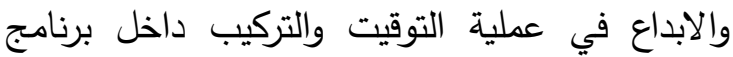

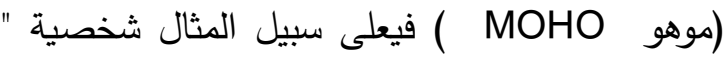
أيمون المجنون " التي اهتم فيها الفنان بالجوانب

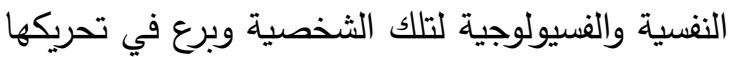

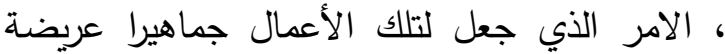

على مستوى العالم العربي. شكل رقم (23) الأن

وهناك مجموعة من الثخصيات الهامة التي تتاولتها

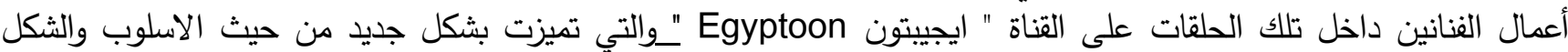
والنسب ـ فنجد شخصية " حمادة " التي اختارها الفنان لتكون بطل مجموعة من الاعمال الفنية الكارتونية المتميزة ، والتي

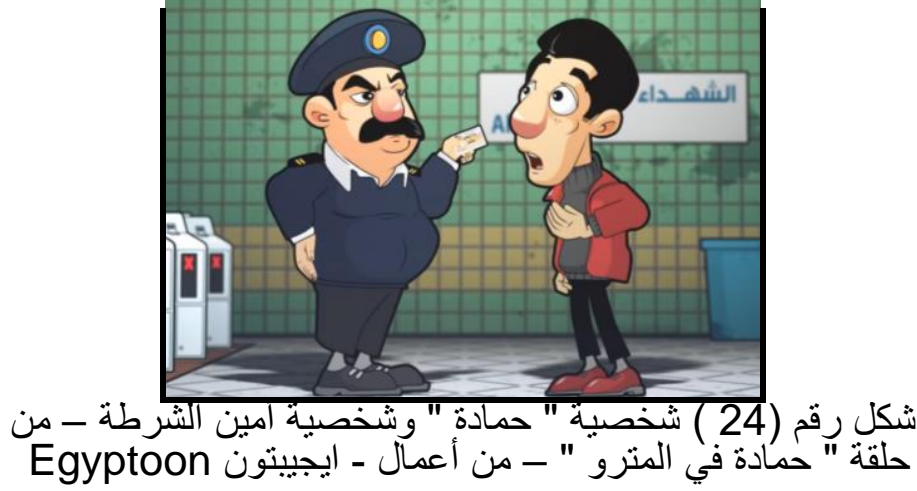

https://www.youtube.com/watch?v=hn8qbSsD38

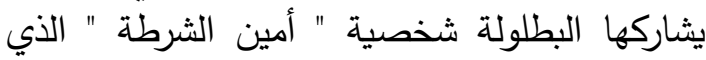
يتحين الفرص لالصاق التهم بالمواطن البائس " حمادة " شكل رقم (24 )

The AMAZING مسلسل (رائعة اوانغ خنيت (AWANG KHENIT The Amazing Awang Khenit رسوم متحركة تليفزيوني ماليزي للأطفال، انتاج

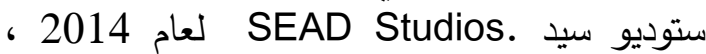

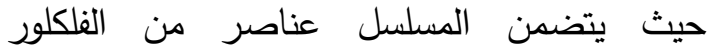
الماليزي والكوميديا الساخرة .شكل رقم (25 ) فئمن

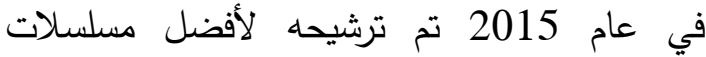
متحركة في مهرجان ماليزيا السينمائي ـ اعتبارًا من

(2) https://ar.wikipedia.org/wiki/\%D8\%A5\%D9\%8A\%D8\%AC\%D9\%8A\%D8\%A8\%D8\%AA\%D9\%88\%D9\%86 
نفس العام ، تم عرض المسلسل أسبوعيًا من قبل جمهور يبلغ 2.4 مليون، كما تم بثه على قناة TV9 ، انتقل أوانج خنيت إلى منى

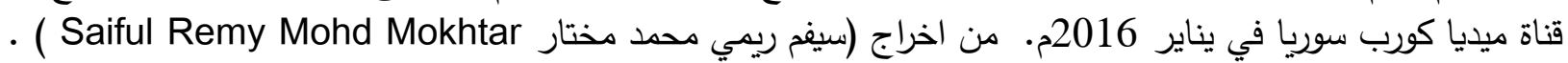

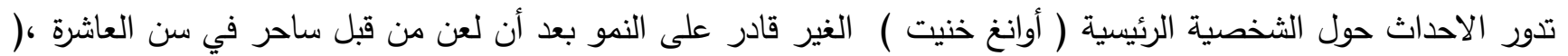

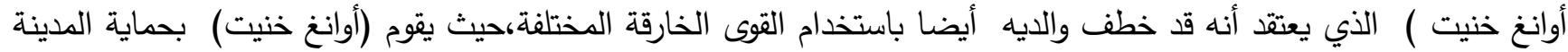

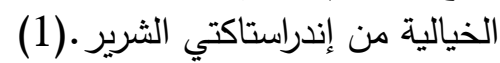

تم تتفيذ المسلسل الكارتوني بتقنية ثنائي الأبعاد باستخدام برنامج ( موهو Moho

\section{النتائج والتوصيات}

نتائج البحث : من خلال الدراسة يمكن استخلاص النتائج الآتية :

• الدور الذي تلعبه المؤثرات البصرية التي يوفرها برنامج ( موهو Moho ) في فن الرسوم المتحركة لخلق جو تفاعلي بين الفيلم والمتلقي يخلق جوا من الاستمتاع بالمشاهدة.

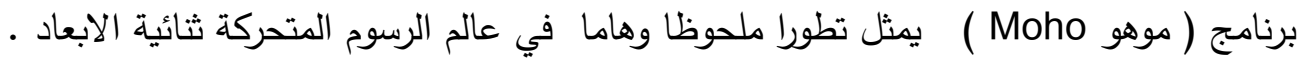

التحريك ببرنامج ( موهو Moho ) له أثر واضح على الرسوم المتحركة ثنائية الابعاد فقد أصبح باستطاعة فناني الرابعاد الرسوم

المتحركة انتاج أعمالا فنية رائعة.

لبرنامج ( موهو Moho) دورا بارزا في مجال الرسوم المتحركة والتي تساعد في تشكيل الجانب الفكري والوجداني من خلال الافكار والأعمال الفنية التى يطرحها لدى المتلقين.

$$
\text { توصيات البحث }
$$

لابد من إنتاج أفلام رسوم متحركة محلية ببرنامج ( موهو Moho ) تحاكي البيئة المصرية بمختلف أطيافها وان كان قد ظهر منها القليل مؤخرا .

إقامة مهرجانات رسوم متحركة ومسابقات دولية كبيرة لعرض أفلام نفذت ببرنامج ( موهو Moho ) لتحفيذ فناني الرسوم

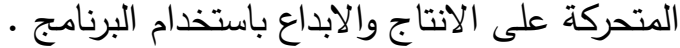

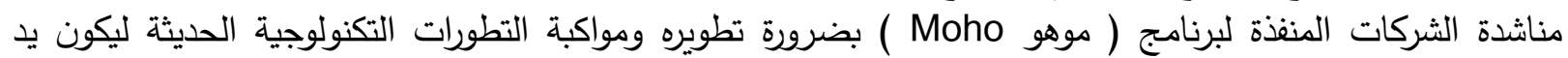
العون لدى الفنانين المبدعين في مجال التحريك.

تضمين تعلم برنامج ( موهو Moho ) ضمن مناهج تعليم فن الرسوم المتحركة لدى طلاب التخصص التص . مراجع البحث

المرجع العربية :

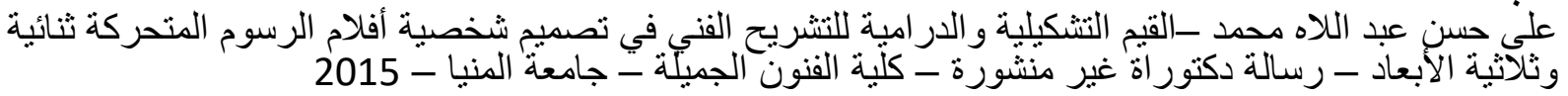

المراجع الأجنبية : الابعاد

- Chad Troftgruben learning Anime Studio packt Publishing Ltd,2014

- Anime studio pro 11users Manual

- Kelly L.Murdock Anime Studio 6 The Official Guide Cengage Learning,2009

المواقع الالكترونية للموضوعات:

• http://web.archive.org/web/20130921214009/http://www.smithmicro.com/about/newspress-detail.aspx?newsid $=414$

- https://www.eskchat.com/article-1607.html

- https://en.wikipedia.org/wiki/The_Amazing_Awang_Khenit

-https://ar.wikipedia.org/wiki/\%D8\%A5\%D9\%8A\%D8\%AC\%D9\%8A\%D8\%A8\%D8\%AA\%D9\%88\%D

$9 \% 86$

${ }^{(1)}$ https://en.wikipedia.org/wiki/The_Amazing_Awang_Khenit 